\title{
Association of vitamin D receptor gene polymorphisms and bronchopulmonary dysplasia
}

\author{
Ozge Altun Koroglu', Huseyin Onay², Bilin Cakmak', Betul Bilgin'1, Mehmet Yalaz'1, Seckin Tunc ${ }^{2}$, Ferda Ozkinay ${ }^{2}$ and \\ Nilgun Kultursay ${ }^{\top}$
}

BACKGROUND: Vitamin D and its receptor (VDR) have important roles in perinatal lung development. The aim of this study was to investigate the relationship between VDR gene polymorphism and bronchopulmonary dysplasia (BPD) in preterm infants. METHODS: VDR Fok I, Bsm I, Apa I, and Taq I polymorphisms were genotyped using restriction fragment length polymorphism in 109 preterm infants (47 with BPD, 62 without BPD).

RESULTS: In univariate analysis, $\mathrm{Ff}$ (odds ratio $(\mathrm{OR})=3.937, \mathrm{P}$ $=0.022,95 \%$ confidence interval $(\mathrm{Cl})=1.22-12.69)$ and $\mathrm{ff}(\mathrm{OR}$ $=5.23, P=0.004,95 \% \mathrm{Cl}=1.69-16.23)$ genotypes of Fok I were associated with the increased risk of BPD; whereas tt genotype of Taq 1 was associated with a protective effect against BPD $(\mathrm{OR}=0.30, P=0.04,95 \% \mathrm{Cl}=0.09-0.94)$. In multivariate logistic regression analysis, variant Fok 1 genotype increased risk of $\mathrm{BPD}(\mathrm{OR}=4.11,95 \% \mathrm{Cl}=1.08-15.68, P=0.038)$ independent of patent ductus arteriosus, sepsis, mechanical ventilation, and surfactant treatment. Taq 1, Bsm 1, and Apa 1 polymorphisms did not have any effect.

CONCLUSION: After adjusting for multiple confounders, VDR Fok 1 polymorphism was associated with the increased frequency of BPD. Further studies are needed to assess the contribution of VDR signaling to the pathogenesis of BPD and to determine if VDR polymorphisms may be suitable for identifying infants at high risk for BPD.

D espite all efforts, bronchopulmonary dysplasia (BPD) continues to be a common problem for preterm infants (1). There is a growing body of evidence showing that BPD is not a disease solely due to environmental insults, but is the result of interactions between environmental and genetic factors (2). Twin studies have shown that even after controlling for covariates, genetic factors account for $53 \%$ of the variance in susceptibility to BPD (3). In the past, components of the innate immune system and antioxidant defenses, mechanisms of vascular and lung remodeling, and surfactant proteins have been the focus of genetic-association studies in BPD $(4,5)$. Candidate genes for further research have been identified in these studies; however, any particular gene or gene pathway was not concluded to have a substantial contribution to the underlying etiology of BPD (5).
Vitamin D has well-established roles in bone metabolism and mineral homeostasis mediated through the Vitamin D receptor (VDR) acting as a ligand-activated transcription factor (6). Other than bone, VDR is expressed in many tissues in the body, including lungs, thymus, $\mathrm{T}$ lymphocytes, neutrophils, antigen-presenting cells, and dendritic cells (7). Consistent with this wide distribution, a role for vitamin $\mathrm{D}$ has been suggested in many diseases, such as cancer, multiple sclerosis, diabetes, and cardiovascular disease through its effects on cell proliferation and immune function (8).

Some of the most important nonendocrine actions of vitamin D are related to innate immunity, components of which have been implicated in the pathogenesis of BPD $(5,7)$. Recent studies have shown that vitamin $\mathrm{D}$ and its receptor may also have important roles in susceptibility to chronic lung diseases through the regulation of genes involved not only in inflammation and immunity, but also in cellular proliferation and differentiation (9). The lack of VDR is associated with early emphysematous changes in the mouse lungs (10). Moreover, an important role for vitamin D has been suggested as a regulator for fetal lung development $(11,12)$. Vitamin D was also reported as a growth factor for alveolar type-II cells, and local elaboration of vitamin D was once considered as a novel mechanism of modulation of epithelial proliferation in the context of lung development and repair (13). Considering its aforementioned roles in regulation of innate immunity, inflammation, lung development, and repair, we thought vitamin $\mathrm{D}$ may be involved in the pathogenesis of BPD. Therefore, we hypothesized that VDR gene polymorphisms may be suitable for predicting patients at high risk for BPD.

\section{RESULTS}

Of the 109 newborns enrolled in the study, 21 infants were diagnosed as mild BPD; 15 infants had moderate BPD and 11 infants had severe BPD, according to published guidelines (14). Antenatal variables were similar between BPD and non-BPD groups (Table 1). Infants with BPD had lower birth weights and smaller gestational ages and required intubation more frequently. Hemodynamically significant patent ductus arteriosus 
(PDA) and sepsis were seen more frequently in infants with BPD (Table 1).

VDR gene polymorphisms' frequencies among study groups are shown in Table 2. In univariate analysis, Ff genotype was associated with a 3.93 times increased risk of BPD $(P=0.022$, $95 \% \mathrm{CI}=1.22-12.69)$ and ff genotype was associated with 5.23 times increased risk of BPD $(P=0.004,95 \% \mathrm{CI}=1.69-16.23)$. For the Taq 1 polymorphism; tt genotype was associated with

Table 1. Clinical characteristics of the study population

\begin{tabular}{|c|c|c|c|c|c|c|}
\hline \multirow{2}{*}{\multicolumn{2}{|c|}{$\begin{array}{l}\text { Clinical } \\
\text { characteristics }\end{array}$}} & \multicolumn{2}{|c|}{ No BPD $(n=62)$} & \multicolumn{2}{|c|}{$\mathrm{BPD}(n=47)$} & \multirow[b]{2}{*}{$P$} \\
\hline & & $n(\%)$ & $\begin{array}{l}\text { Mean } \\
( \pm \text { SD })\end{array}$ & $n(\%)$ & $\begin{array}{l}\text { Mean } \\
( \pm \text { SD })\end{array}$ & \\
\hline \multicolumn{7}{|c|}{ Infants'characteristics } \\
\hline \multicolumn{3}{|c|}{ Birth weight (g) } & $\begin{array}{l}1,523.79 \\
(354.36)\end{array}$ & & $\begin{array}{c}980.04 \\
(252.17)\end{array}$ & $<0.001$ \\
\hline \multicolumn{3}{|c|}{ Gestational age (wk) } & $\begin{array}{l}30.17 \\
(1.92)\end{array}$ & & $\begin{array}{l}27.19 \\
(2.04)\end{array}$ & $<0.001$ \\
\hline \multicolumn{2}{|l|}{$\mathrm{C} / \mathrm{S}$} & $49(79)$ & & $33(70.2)$ & & 0.371 \\
\hline \multicolumn{2}{|c|}{ Male gender } & $35(56.5)$ & & $23(48.9)$ & & 0.446 \\
\hline \multicolumn{2}{|c|}{ Apgar score at $1 \mathrm{~min}$} & & $6.7(1.85)$ & & $\begin{array}{c}3.91 \\
(2.00)\end{array}$ & $<0.001$ \\
\hline \multicolumn{2}{|c|}{ Apgar score at $5 \mathrm{~min}$} & & $8.79(1.30)$ & & $\begin{array}{c}6.98 \\
(1.59)\end{array}$ & $<0.001$ \\
\hline \multicolumn{2}{|c|}{$\begin{array}{l}\text { Surfactant } \\
\text { treatment }\end{array}$} & $18(29)$ & & $39(83)$ & & $<0.001$ \\
\hline \multicolumn{2}{|c|}{$\begin{array}{l}\text { Mechanical } \\
\text { ventilation }\end{array}$} & $22(35.5)$ & & $43(91.5)$ & & $<0.001$ \\
\hline \multicolumn{2}{|c|}{$\begin{array}{l}\text { Duration of } \\
\text { mechanical } \\
\text { ventilation (d) }\end{array}$} & & $3.59(3.27)$ & & $\begin{array}{l}41.95 \\
(52.25)\end{array}$ & $<0.001$ \\
\hline \multicolumn{2}{|c|}{$\begin{array}{l}\text { Duration of oxygen } \\
\text { therapy (d) }\end{array}$} & & $3.37(5.30)$ & & $\begin{array}{l}79.02 \\
(58.56)\end{array}$ & $<0.001$ \\
\hline \multicolumn{2}{|c|}{ Significant PDA } & $10(16.1)$ & & $30(63.8)$ & & $<0.001$ \\
\hline \multirow[t]{3}{*}{ Sepsis } & No sepsis & $39(62.9)$ & & $6(12.8)$ & & $<0.001$ \\
\hline & $\begin{array}{l}\text { Clinical } \\
\text { sepsis }\end{array}$ & $16(25.8)$ & & $30(63.8)$ & & \\
\hline & $\begin{array}{l}\text { Proven } \\
\text { sepsis }\end{array}$ & $7(11.3)$ & & $11(23.4)$ & & \\
\hline \multicolumn{2}{|c|}{$\begin{array}{l}\text { Duration of } \\
\text { hospitalization }\end{array}$} & $\begin{array}{l}23.68 \\
(18.92)\end{array}$ & & $\begin{array}{l}92.55 \\
(55.67)\end{array}$ & & $<0.001$ \\
\hline \multicolumn{2}{|c|}{ Survival } & $62(100)$ & & $43(91.5)$ & & 0.032 \\
\hline \multicolumn{7}{|c|}{ Maternal characteristics } \\
\hline \multicolumn{2}{|c|}{ Preeclampsia } & $10(16.1)$ & & $10(21.3)$ & & 0.618 \\
\hline \multicolumn{2}{|l|}{ PROM } & $13(21)$ & & $15(23.3)$ & & 0.184 \\
\hline \multicolumn{2}{|c|}{ Chorioamnionitis } & $5(8.1)$ & & $3(6.4)$ & & 0.521 \\
\hline \multicolumn{7}{|c|}{ Treatments before delivery } \\
\hline \multicolumn{2}{|c|}{ Tocolysis } & $46(74.2)$ & & $37(78.7)$ & & 0.654 \\
\hline \multicolumn{2}{|c|}{ Antibiotics } & $23(37.1)$ & & $24(51.1)$ & & 0.174 \\
\hline \multicolumn{2}{|c|}{ ANCS (yes/no) } & $54(87.1)$ & & $39(83)$ & & 0.593 \\
\hline \multirow[t]{2}{*}{ ANCS } & Partial & $22(35.5)$ & & $13(27.7)$ & & 0.642 \\
\hline & Complete & $32(51.6)$ & & $26(55.3)$ & & \\
\hline
\end{tabular}

ANCS, antenatal corticosteroids; BPD, bronchopulmonary dysplasia; C/S, cesarean section; PDA, patent ductus arteriosus; PROM, premature rupture of membranes. a protective effect against $\mathrm{BPD}(\mathrm{OR}=0.30, P=0.04,95 \% \mathrm{CI}$ $=0.098-0.94)$. Bsm 1 and Apa 1 polymorphisms' frequencies were not significantly different between two groups.

In univariate analysis of potential clinical risk factors for the development of BPD; birth weight, gestational age, Apgar scores at the first and fifth minute, surfactant treatment, mechanical ventilation, and clinical and culture-proven sepsis were associated with increased risk of BPD (Table 3). These variables were included in multivariate logistic regression analysis. In this model, variant Fok 1 genotype increased the risk of $\mathrm{BPD}(\mathrm{OR}=4.11,95 \% \mathrm{CI}=1.08-15.68, P=0.038)$ independent of significant PDA, clinical and culture-proven sepsis, mechanical ventilation, and surfactant treatment (Table 4). However, Taq 1, Bsm 1, and Apa 1 polymorphisms did not have any effect in the same model. When we analyzed the impact of variant Fok 1 genotype after controlling for gestational age and birth weight; we did not see a significant effect $(P=0.139$, OR $=2.928,95 \% \mathrm{CI}=0.707-12.131$ ).

Achieved power of the study was calculated as $85 \%$ for Fok 1 gene, $44 \%$ for Taq 1 gene, 17\% for Bsm 1 and 15\% for Apa 1 genes, depending on the distribution of normal genotype between the groups with and without BPD.

\section{DISCUSSION}

For the first time in the literature, our data show that VDR Fok 1 polymorphism may be a significant risk factor for BPD in preterm infants, independent of other risk factors, such as PDA, sepsis, and mechanical ventilation. On the other hand, the protective effect of Taq 1 polymorphism that appeared in

Table 2. Frequency distribution of VDR gene polymorphisms in control and BPD groups

\begin{tabular}{|c|c|c|c|c|c|}
\hline Variable & $\begin{array}{c}\text { No BPD }(n=62), \\
n(\%)\end{array}$ & $\begin{array}{c}\mathrm{BPD}(n=47) \\
n(\%)\end{array}$ & $P$ & $\begin{array}{c}\text { OR } \\
(95 \% \mathrm{Cl})\end{array}$ & $P$ \\
\hline \multicolumn{6}{|c|}{ VDR genotype } \\
\hline \multicolumn{6}{|l|}{ Fok 1} \\
\hline $\mathrm{FF}$ & $22(35.5)$ & $5(10.6)$ & & & \\
\hline $\mathrm{Ff}$ & $19(30.6)$ & $17(36.2)$ & 0.01 & $3.93(1.22-12.69)$ & 0.022 \\
\hline $\mathrm{Ff}$ & $21(33.9)$ & $25(53.2)$ & & $5.238(1.690-16.234)$ & 0.004 \\
\hline \multicolumn{6}{|l|}{ Taq 1} \\
\hline $\mathrm{TT}$ & $17(27.4)$ & $21(44.7)$ & & & \\
\hline $\mathrm{Tt}$ & $29(46.8)$ & $20(42.6)$ & 0.098 & $0.55(0.23-1.31)$ & 0.726 \\
\hline $\mathrm{Tt}$ & $16(25.8)$ & $6(12.8)$ & & $0.30(0.09-0.94)$ & 0.040 \\
\hline \multicolumn{6}{|l|}{ Bsm 1} \\
\hline BB & $22(35.5)$ & $12(25.5)$ & & & \\
\hline $\mathrm{Bb}$ & $28(46.8)$ & $18(38.3)$ & 0.136 & $1.17(0.47-2.95)$ & 0.726 \\
\hline $\mathrm{Bb}$ & $12(19.4)$ & $17(36.2)$ & & $2.59(0.93-7.20)$ & 0.067 \\
\hline \multicolumn{6}{|l|}{$A P a 1$} \\
\hline AA & $18(29.0)$ & $18(38.3)$ & & & \\
\hline $\mathrm{Aa}$ & $35(56.5)$ & $19(40.4)$ & 0.249 & $0.54(0.23-1.28)$ & 0.164 \\
\hline $\mathrm{Aa}$ & $9(14.5)$ & $10(21.3)$ & & $1.11(0.36-3.38)$ & 0.853 \\
\hline
\end{tabular}

BPD, bronchopulmonary dysplasia; Cl, confidence interval; OR, odds ratio; VDR, vitamin D receptor. 
the univariate analysis seems to be confounded with other covariates in our study group.

Genetic alterations of the VDR gene are thought to be leading to important defects of gene activation resulting in protein sequence changes (8). In humans, the VDR gene locus is found at the 12q13.1 region (15). Although there are more than 200 polymorphisms of the VDR gene; Fok I, Bsm I, Apa I, and Taq I are the most commonly described restriction fragment length polymorphisms. Being located in exon 2, Fok 1 is different from Bsm I, Apa I, and Taq I polymorphisms that are located between exons 8 and 9, and results in the production of a longer and less active form of protein (16). Thus, Fok 1 polymorphism that appears to be associated with BPD in our study may result in a decreased activity of VDR. Although a protective effect for Taq 1 is also seen in this study, this may not represent a consistent trend as Taq 1 is known to be a silent base change that does not modify the encoded amino acid (17).

As far as we know, VDR gene polymorphisms have been the focus of research in preterm newborns only once. Funke et al. (18) investigated the influence of Taq 1 polymorphism of VDR on bone disease of preterm infants in 65 newborns and demonstrated that the common occurrence of heterozygote $\mathrm{Tt}$ restriction fragment length polymorphisms of the VDR gene and CC polymorphism of COLIA 1 gene was a protective factor against bone disease of prematurity. The distribution of Taq 1 polymorphism of VDR gene was not significantly different when analyzed separately in that study either.

Table 3. Univariate analysis of clinical variables influencing the risk of BPD

\begin{tabular}{|c|c|c|c|c|}
\hline \multirow{2}{*}{\multicolumn{2}{|c|}{$\begin{array}{l}\text { Clinical characteristics } \\
\text { Birth weight (g) }\end{array}$}} & \multicolumn{2}{|c|}{ BPD OR (Cl) } & \multirow{2}{*}{$\begin{array}{c}P \\
<0.001\end{array}$} \\
\hline & & 0.994 & $0.992-0.996$ & \\
\hline \multicolumn{2}{|c|}{ Gestational age (wk) } & 0.512 & $0.399-0.657$ & $<0.001$ \\
\hline \multicolumn{2}{|l|}{$\mathrm{C} / \mathrm{S}$} & 0.625 & $0.261-1.499$ & 0.293 \\
\hline \multicolumn{2}{|c|}{ Male gender } & 0.739 & $0.345-0.649$ & 0.437 \\
\hline \multicolumn{2}{|c|}{ Apgar score at $1 \mathrm{~min}$} & 0.499 & $0.384-0.649$ & $<0.001$ \\
\hline \multicolumn{2}{|c|}{ Apgar score at $5 \mathrm{~min}$} & 0.401 & $0.272-0.590$ & $<0.001$ \\
\hline \multicolumn{2}{|c|}{ Surfactant treatment } & 11.917 & $6.195-61.671$ & $<0.001$ \\
\hline \multicolumn{2}{|c|}{ Mechanical ventilation } & 19.545 & $6.195-61.671$ & $<0.001$ \\
\hline \multicolumn{2}{|c|}{ Significant PDA } & 9.176 & $3.727-22.596$ & $<0.001$ \\
\hline \multirow[t]{3}{*}{ Sepsis } & No sepsis & 1 & & \\
\hline & Clinical sepsis & 12.187 & $4.256-34.98$ & $<0.001$ \\
\hline & Proven sepsis & 10.214 & $2.842-36.713$ & $<0.001$ \\
\hline \multicolumn{2}{|l|}{ PROM } & 1.885 & $0.789-4.501$ & 0.154 \\
\hline \multicolumn{2}{|c|}{ Chorioamnionitis } & 0.777 & $0.176-3.430$ & 0.739 \\
\hline \multirow[t]{3}{*}{ ANCS } & No ANCS & 1 & & \\
\hline & Partial ANCS & 0.591 & $0.179-1.954$ & 0.389 \\
\hline & $\begin{array}{l}\text { Complete } \\
\text { ANCS }\end{array}$ & 0.813 & $0.268-2.461$ & 0.713 \\
\hline
\end{tabular}

ANCS, antenatal corticosteroids; BPD, bronchopulmonary dysplasia; Cl, confidence interval; $C / S$, cesarean section; $\mathrm{OR}$, odds ratio; $\mathrm{PDA}$, patent ductus arteriosus; $\mathrm{PROM}$, premature rupture of membranes.
The role of Fok 1 polymorphism in the pathogenesis of BPD may be related to the actions of vitamin D in the innate immune system that carries particular importance for premature infants. VDR gene polymorphisms may limit the ability to fight pathogens and make premature infants vulnerable to postnatal infections and BPD. Decreased vitamin D levels are shown to be associated with acute lower respiratory tract infections not only in older children, but also in newborns (19-21). Moreover, the presence of VDR gene polymorphisms may lead to higher incidence of certain respiratory infections in children $(22,23)$. Walker et al. $(24)$ have shown the impact of cord blood vitamin $\mathrm{D}$ status on innate immune responses by demonstrating altered in vitro monocyte responses via TLR-induced antimicrobial production in vitamin D deficient term newborns. However, a recent study failed to demonstrate any relationship between cord blood vitamin $\mathrm{D}$ levels and $\mathrm{T}$ lymphocytes in newborns (25). The paucity of phenotypic correlation of vitamin $\mathrm{D}$ with immune abnormalities in term newborns may be due to genotypic variations that alter the functions of VDR. Thus, the effect of vitamin $\mathrm{D}$ on the innate immune system of newborns may or may not be related to serum vitamin $\mathrm{D}$ levels. In view of the fact that our study lacks detailed evaluation of immune function and vitamin D levels, definitive explanation of such a relationship is beyond the limits of this research.

Vitamin D and VDR are also involved in the pathogenesis of chronic lung diseases in adults through epigenetic mechanisms involving inflammation, immunity, and cellular proliferation and differentiation (9). Sundar et al. (10) reported that the deletion of VDR led to the increased influx of inflammatory cells, increased proinflammatory mediators, and upregulation of matrix metalloproteinases in the lungs associated with airway enlargement and decline in lung function resulting in early emphysematous changes. These mechanisms may also be valid for the involvement of vitamin $\mathrm{D}$ in pathogenesis of BPD.

An additional biological function of vitamin $\mathrm{D}$ in early human development is regulation of fetal lung maturation. Previously, disturbed lung mechanics in rachitic rat pups born to vitamin D-deficient mothers was thought to be related to abnormal growth of the lungs caused by abnormal alveolarization (26). The role of vitamin D as a local mediator of epithelial-mesenchymal cell interactions in the developing rat

Table 4. Multivariate logistic regression analysis of variables associated with the risk of BPD

\begin{tabular}{lccc}
\hline & \multicolumn{2}{c}{ BPD } & \\
\cline { 2 - 3 } & OR & Cl & $P$ \\
\hline Variant Fok genotype & 4.115 & $1.08-15.68$ & 0.038 \\
Significant PDA & 3.668 & $1.20-11.11$ & 0.022 \\
Clinical sepsis & 3.694 & $0.97-13.96$ & 0.054 \\
Proven sepsis & 2.507 & $0.51-12.30$ & 0.257 \\
Surfactant & 1.010 & $0.19-5.12$ & 0.990 \\
Mechanical ventilation & 10.591 & $1.71-65.40$ & 0.011 \\
\hline
\end{tabular}

$\mathrm{BPD}$, bronchopulmonary dysplasia; $\mathrm{Cl}$, confidence interval; $\mathrm{OR}$, odds ratio. 
lungs has been demonstrated (11). Vitamin D is also considered as a growth factor for alveolar type-II cells, the cells that are responsible for alveolar epithelial cell proliferation during growth, development and in response to lung injury; due to its effects stimulating DNA synthesis in these cells (13). Sakurai et al. (12) have demonstrated the critical role of vitamin D in perinatal lung maturation by stimulation of alveolar epithelialmesenchymal interactions, and also by modulation of lipofibroblast apoptosis; resulting in increased surfactant synthesis and alveolar septal thinning. Although vitamin D might play an important role in the alveolarization process, difficulties in induction of these effects via systemic delivery of pharmacological agents have also been reported (27).

$\mathrm{BPD}$ has a complex pathogenesis involving multiple insults to the immature lungs, resulting in varying degrees of alveolar simplification, structural, and functional modifications of arterioles and bronchioles (28). Disturbance of VDR function may be important for the developing lungs, especially for alveolarization. Since an independent effect of variant VDR Fok 1 genotype on BPD risk was not demonstrated after controlling for birth weight and gestational age; VDR genotype may be related to preterm birth and low birth weight for increasing the risk of BPD, although this could not be elucidated in the current study.

There are regional differences in the reported BPD rates from different studies. BPD rates ranged from 10.2 to $24.8 \%$ for infants between 23-31 wk of gestations in the MOSIAC cohort of 10 European regions (29). The overall incidence of $\mathrm{BPD}$ or death was $52 \%$; ranging from 32 to $74 \%$ across NICHD Neonatal Research Network centers in infants below 1,250 g (30). In Korea; the incidence of BPD/death was $33 \%$ for preterm infants born before week 32 of gestational age (31). Israel Neonatal Network data give the incidence of BPD as $13.7 \%$ among infants with birth weights below $1,500 \mathrm{~g}$ surviving to a postmenstrual age of $36 \mathrm{wk}$ (32).

The incidence of BPD in our study may seem higher than some of these studies. BPD definition used in different studies may be a factor causing variability. It is known that the use of physiologic definition reduces the variability between different centers and the incidence of BPD up to $10 \%$ at individual centers (1). In addition to that, our patient population consist mostly of infants of mothers with inadequate antenatal care. Being a tertiary center in our region also brings the load of complicated cases that necessitates multidisciplinary care of mothers and infants with a high risk of mortality and morbidity. With the more common use of noninvasive ventilation modes; we have seen a considerable decline in our BPD rates.

Our study was performed in a single center and enrolled a high-risk population of 109 preterm infants with similar ethnic backgrounds who were admitted in the same time frame. Infants were followed according to established unit policies. However, while single-center studies overcome ethnicity and environmental confounders at least partially, there is also a limitation of available cases over a time period. Interpretation of polymorphism studies requires attention for generalization of the data across different ethnic groups. Due to the lack of
Table 5. PCR primers used in VDR gene polymorphism genotyping

\begin{tabular}{|c|c|c|}
\hline $\begin{array}{l}\text { VDR } \\
\text { polymorphism }\end{array}$ & Primer & $\begin{array}{l}\text { PCR annealing } \\
\text { temperature }\left({ }^{\circ} \mathrm{C}\right)\end{array}$ \\
\hline \multirow[t]{2}{*}{ Fok I } & F:CCCTGGCACTGACTCTGCTC & 60 \\
\hline & R:GGAAACACCTTGCTTCTTCTCC & \\
\hline \multirow[t]{2}{*}{ Bsm I } & F:AGTGTGCAGGCGATTCGTAG & 60 \\
\hline & R: ATAGGCAGAACCATCTCTCAG & \\
\hline \multirow[t]{2}{*}{ Apa I } & F:AGCATGGACAGGGAGCAA & 61.9 \\
\hline & R: CCTGTGCCTTCTTCTCTATCC & \\
\hline \multirow[t]{2}{*}{ Taq I } & F: CCTGTGCCTTCTTCTCTATCC & 54 \\
\hline & R: AGCCTGAGTGCAGCATGA & \\
\hline
\end{tabular}

VDR, vitamin D receptor.

histopathological data, the contribution of histological chorioamnionitis to the risk of BPD could not be assessed in this study whilst the contributions of VDR polymorphisms were analyzed in the multivariate model. It should also be kept in mind that this study was not restricted only to infants below $28 \mathrm{wk}$ of gestation who were at substantial risk for BPD. Thus, the control group included more mature infants in whom the risk of BPD was lower due to genetic and environmental factors.

\section{Conclusion}

In conclusion, our findings showing VDR Fok 1 polymorphism as a significant risk factor for BPD necessitates further research in different populations. Nevertheless, in light of newly discovered extraskeletal functions of vitamin $\mathrm{D}$, this relationship, which persists after adjusting for multiple confounders, suggests that VDR may be involved in the pathogenesis of BPD and VDR gene polymorphisms may be suitable to predict the infants at high risk for BPD, in future possibly helping to guide personalized care.

\section{METHODS}

\section{Patients}

One hundred and nine preterm infants born at gestational age $\leq 32 \mathrm{wk}$ were admitted to the Neonatal Intensive Care Unit at Ege University Children's Hospital, and were enrolled in the study between September 2008 and September 2011. Forty-seven of the infants were diagnosed with BPD according to the National Institutes of Child Health and Human Development/National Heart, Lung, and Blood Institute and Office of Rare Diseases workshop definition (14). The remaining 62 infants were preterm newborns admitted consecutively to the BPD group of infants in the same period. Infants who did not survive until postconceptional $36 \mathrm{wk}$ and infants with congenital malformations were excluded. During the patient recruitment period of $36 \mathrm{mo} ; 302$ preterm infants born at gestational age $\leq 32 \mathrm{wk}$ were admitted to our Neonatal Intensive Care Unit. Fifty-nine of those infants died before postconceptional age $36 \mathrm{wk}$; 193 infants survived without BPD and 47 infants survived with BPD. Patient recruitment was done among survivors at postconceptional $36 \mathrm{wk}$; preterm infants without BPD born in the $48 \mathrm{~h}$ following a BPD patient were recruited as controls. All infants were born at the main Ege University Hospital and were from Turkish families living in the Aegean region of Turkey. Prenatal history and neonatal complications were documented. The study was approved by the Local Ethics Committee of Ege University Faculty of Medicine and written informed consent was obtained from parents of all infants. 
All Neonatal Intensive Care Unit patients received calcium, phosphorous, and vitamin D supplementation according to the European Society of Paediatric Gastroenterology, Hepatology and Nutrition guidelines $(33,34)$. Per our institutional policy, early surfactant treatment was given to the infants born before $32 \mathrm{wk}$ with respiratory distress in the first hours of life; older infants who had clinical and radiological signs of respiratory distress syndrome received rescue surfactant treatment. Primary mode of ventilation was synchronized intermittent mandatory ventilation with rates of $30-40$ breaths/min, inspiratory time of $0.35-0.38 \mathrm{~s}$; PEEP (positive end-expiratory pressure) of $4-5 \mathrm{cmH}_{2} \mathrm{O}$ targeting a tidal volume of $4 \mathrm{ml} / \mathrm{kg}$. Peak inspiratory pressure was adjusted to achieve an optimal chest wall rise and tidal volume. The target oxygen saturation range was $88-94 \%$, and target ranges for $\mathrm{pH}$ and $\mathrm{PcO}_{2}$ in the first week of life were 7.25-7.35 and 40-60, respectively. We considered extubation to nasal (continuous positive airway pressure) $\mathrm{CPAP}$ when peak inspiratory pressure $=15-16 \mathrm{cmH}_{2} \mathrm{O}, \mathrm{PEEP}$ $=4-5 \mathrm{cmH}_{2} \mathrm{O}$, rate $=12-15 / \mathrm{min}, \mathrm{FiO}_{2} \leq 30 \%$. Study infants were evaluated by echocardiography in the first $3 \mathrm{~d}$ of life for the presence of PDA. Pharmacological treatment with ibuprofen was given if hemodynamically significant PDA was diagnosed (35). Clinical sepsis was diagnosed in the presence of two typical clinical signs accompanied by at least two laboratory signs. Clinical signs used for diagnosis of sepsis included temperature instability (fever or hypothermia), cardiovascular deterioration (bradycardia, tachycardia, hypotension, poor peripheral circulation), respiratory deterioration (apnea, increase in oxygen and/or ventilation requirement), gastrointestinal deterioration (feeding intolerance, abdominal distention, absent bowel sounds, bloody stools), and neurologic detoriation (convulsion, hypotonia, irritability). Laboratory parameters included increased C-reactive protein $(>10 \mathrm{mg} / \mathrm{l})$ and/or $\mathrm{I} / \mathrm{T}$ (immature/total) ratio $(>0.2)$, pathological white blood cell count $\left(<5,000\right.$ or $\left.>20,000 / \mathrm{mm}^{3}\right)$ and thrombocytopenia $\left(<100,000 / \mathrm{mm}^{3}\right)$, metabolic acidosis.

Culture-proven sepsis was defined as positive blood culture results in the presence of clinical signs. Two doses of betamethasone given $24 \mathrm{~h}$ to $7 \mathrm{~d}$ before birth were considered as a complete course of antenatal corticosteroids; any steroids administered beyond this range were classified as a partial course. Chorioamnionitis was diagnosed clinically in the presence of maternal fever, leukocytosis, tachycardia, uterine tenderness, and foul-smelling amniotic fluid (36). Histological chorioamnionitis could not be assessed due to lack of histopathological data.

\section{Genetic Analysis}

Venous whole-blood samples were collected in ethylenediaminetetraacetate tubes and stored at $-20{ }^{\circ} \mathrm{C}$ until processing. DNA was extracted from 200- $\mu$ l whole-blood using the Invisorb Spin Micro DNA Kit (Stratec Molecular GmbH, Berlin, Germany). Polymerase chain reaction (PCR) was performed with the primers listed in Table 5 . Following PCR reactions, all four polymorphisms (Fok I, Bsm I, Apa I, and Taq I) in the VDR gene were genotyped using restriction fragment length polymorphisms. The presence of a restriction site is designated by a lowercase letter (mutant allele) and its absence by an uppercase letter (wild type allele) for Bsm I, Apa I, and Taq I polymorphisms. Differently, mutant allele remains uncut for Fok I polymorphism.

\section{Statistical Analysis}

Statistical Package for the Social Sciences (SPSS) for Windows 19.0 software (IBM, Armonk, NY) was used to evaluate the data. These data are summarized as mean \pm SD and percentages. $\chi^{2}$ test, Fisher exact test, independent sample $t$-test (with 95\% CI), and ANOVA test were performed to determine differences between the study groups as appropriate. The relative contribution of different variables was assessed by univariate analysis. Multivariate logistic regression analyses were performed with VDR genotypes and clinical variables associated with the risk of BPD. Statistical significance was considered at $P<0.05$. Power analyses of the study were done by $\mathrm{G}$ Power 3.0.8 Software (Heinreich Heine Universitat, Dusseldorf, Germany), Heinreich Heine Universität, Dusseldorf, Germany.

\section{ACKNOWLEDGMENTS}

We acknowledge Mehmet Orman from the Department of Biostatistics, Ege University Faculty of Medicine, for his assistance with the statistical analysis.

\section{STATEMENT OF FINANCIAL SUPPORT}

This study was supported by a grant (2011-TIP-086) to N.K. from the Ege University Faculty of Medicine, Izmir, Turkey.

Disclosure: The authors declare that they have no conflict of interest.

\section{REFERENCES}

1. Trembath A, Laughon MM. Predictors of bronchopulmonary dysplasia. Clin Perinatol 2012;39:585-601.

2. Bhandari A, Bhandari V. Pitfalls, problems, and progress in bronchopulmonary dysplasia. Pediatrics 2009;123:1562-73.

3. Bhandari V, Bizzarro MJ, Shetty A, et al. Familial and genetic susceptibility to major neonatal morbidities in preterm twins. Pediatrics 2006;117:19016.

4. Lavoie PM, Dubé MP. Genetics of bronchopulmonary dysplasia in the age of genomics. Curr Opin Pediatr 2010;22:134-8.

5. Shaw GM, O'Brodovich HM. Progress in understanding the genetics of bronchopulmonary dysplasia. Semin Perinatol 2013;37:85-93.

6. Misra M, Pacaud D, Petryk A, Collett-Solberg PF, Kappy M. Vitamin D deficiency in children and its management: review of current knowledge and recommendations. Pediatrics 2008;122:398-417.

7. White JH. Vitamin D signaling, infectious diseases, and regulation of innate immunity. Infect Immun 2008;76:3837-43.

8. Valdivielso JM, Fernandez E. Vitamin D receptor polymorphisms and diseases. Clin Chim Acta 2006;371:1-12.

9. Sundar IK, Rahman I. Vitamin d and susceptibility of chronic lung diseases: role of epigenetics. Front Pharmacol 2011;2:50.

10. Sundar IK, Hwang JW, Wu S, Sun J, Rahman I. Deletion of vitamin D receptor leads to premature emphysema/COPD by increased matrix metalloproteinases and lymphoid aggregates formation. Biochem Biophys Res Commun 2011;406:127-33.

11. Nguyen TM, Guillozo H, Marin L, Tordet C, Koite S, Garabedian M. Evidence for a vitamin $\mathrm{D}$ paracrine system regulating maturation of developing rat lung epithelium. Am J Physiol 1996;271(3 Pt 1):L392-9.

12. Sakurai R, Shin E, Fonseca S, et al. 1alpha,25(OH)2D3 and its 3-epimer promote rat lung alveolar epithelial-mesenchymal interactions and inhibit lipofibroblast apoptosis. Am J Physiol Lung Cell Mol Physiol 2009;297:L496-505.

13. Edelson JD, Chan S, Jassal D, Post M, Tanswell AK. Vitamin D stimulates DNA synthesis in alveolar type-II cells. Biochim Biophys Acta 1994;1221:159-66.

14. Jobe AH, Bancalari E. Bronchopulmonary dysplasia. Am J Respir Crit Care Med 2001;163:1723-9.

15. Uitterlinden AG, Fang Y, Van Meurs JB, Pols HA, Van Leeuwen JP. Genetics and biology of vitamin D receptor polymorphisms. Gene 2004;338:143-56.

16. Ames SK, Ellis KJ, Gunn SK, Copeland KC, Abrams SA. Vitamin D receptor gene Fok1 polymorphism predicts calcium absorption and bone mineral density in children. J Bone Miner Res 1999;14:740-6.

17. Uitterlinden AG, Fang Y, Bergink AP, van Meurs JB, van Leeuwen HP, Pols HA. The role of vitamin D receptor gene polymorphisms in bone biology. Mol Cell Endocrinol 2002;197:15-21.

18. Funke S, Morava E, Czakó M, Vida G, Ertl T, Kosztolányi G. Influence of genetic polymorphisms on bone disease of preterm infants. Pediatr Res 2006;60:607-12.

19. Muhe L, Lulseged S, Mason KE, Simoes EA. Case-control study of the role of nutritional rickets in the risk of developing pneumonia in Ethiopian children. Lancet 1997;349:1801-4.

20. Wayse V, Yousafzai A, Mogale K, Filteau S. Association of subclinical vitamin D deficiency with severe acute lower respiratory infection in Indian children under 5 y. Eur J Clin Nutr 2004;58:563-7.

21. Karatekin G, Kaya A, Salihoğlu O, Balci H, Nuhoğlu A. Association of subclinical vitamin D deficiency in newborns with acute lower respiratory infection and their mothers. Eur J Clin Nutr 2009;63:473-7.

22. Roth DE, Jones AB, Prosser C, Robinson JL, Vohra S. Vitamin D receptor polymorphisms and the risk of acute lower respiratory tract infection in early childhood. J Infect Dis 2008;197:676-80.

23. Kresfelder TL, Janssen R, Bont L, Pretorius M, Venter M. Confirmation of an association between single nucleotide polymorphisms in the VDR gene 
with respiratory syncytial virus related disease in South African children. J Med Virol 2011;83:1834-40.

24. Walker VP, Zhang X, Rastegar I, et al. Cord blood vitamin D status impacts innate immune responses. J Clin Endocrinol Metab 2011;96:1835-43.

25. Guven A, Ecevit A, Sozer O, Tarcan A, Ozbek N. Correlation between the cord vitamin D levels and regulatory T cells in newborn infants. Eur J Pediatr 2012;171:1161-6.

26. Gaultier C, Harf A, Balmain N, Cuisinier-Gleizes P, Mathieu H. Lung mechanics in rachitic rats. Am Rev Respir Dis 1984;130:1108-10.

27. Ormerod AK, Xing Z, Pedigo NG, Mishra A, Kaetzel DM. The calcitriol analogue EB1089 impairs alveolarization and induces localized regions of increased fibroblast density in neonatal rat lung. Exp Lung Res 2008;34:155-82.

28. Albertine KH. Progress in understanding the pathogenesis of BPD using the baboon and sheep models. Semin Perinat 2013;37:60-8.

29. Gortner L, Misselwitz B, Milligan D, et al. Rates of bronchopulmonary dysplasia in very preterm neonates in Europe: results from the MOSAIC cohort. Neonatology 2011;99:112-7.

30. Ambalavanan N, Walsh M, Bobashev G, et al. Intercenter differences in bronchopulmonary dysplasia or death among very low birth weight infants. Pediatrics 2011;127:e106-16.

31. Choi CW, Kim BI, Kim EK, Song ES, Lee JJ. Incidence of bronchopulmonary dysplasia in Korea. J Korean Med Sci 2012;27:914-21.
32. Klinger G, Sokolover N, Boyko V, Sirota L, Lerner-Geva L, Reichman B. Israel Neonatal Network. Perinatal risk factors for bronchopulmonary dysplasia in a national cohort of very-low-birthweight infants. Am J Obstet Gynecol 2013;208:115 e1-9.

33. Koletzko B, Goulet O, Hunt J, Krohn K, Shamir R; Parenteral Nutrition Guidelines Working Group; European Society for Clinical Nutrition and Metabolism; European Society of Paediatric Gastroenterology, Hepatology and Nutrition (ESPGHAN); European Society of Paediatric Research (ESPR). 1. Guidelines on Paediatric Parenteral Nutrition of the European Society of Paediatric Gastroenterology, Hepatology and Nutrition (ESPGHAN) and the European Society for Clinical Nutrition and Metabolism (ESPEN), Supported by the European Society of Paediatric Research (ESPR). J Pediatr Gastroenterol Nutr 2005;41:Suppl 2:S1-87.

34. Agostoni C, Buonocore G, Carnielli VP, et al. Enteral nutrient supply for preterm infants: commentary from the European Society of Paediatric Gastroenterology, Hepatology and Nutrition Committee on Nutrition. J Pediatr Gastroenterol Nutr 2010;50:85-91.

35. Alagarsamy S, Chhabra M, Gudavalli M, Nadroo AM, Sutija VG, Yugrakh D. Comparison of clinical criteria with echocardiographic findings in diagnosing PDA in preterm infants. J Perinat Med 2005;33: $161-4$.

36. Gibbs RS, Duff P. Progress in pathogenesis and management of clinical intraamniotic infection. Am J Obstet Gynecol 1991;164(5 Pt 1):1317-26. 